\title{
Manajemen Kepala Sekolah dalam Menumbuhkan Kompetensi Sosial di Madrasah Ibtidaiyah Muhammadiyah 10 Karang Anyar Rejang Lebong
}

\author{
Murni Yanto \\ Institut Agama Islam Negeri Curup \\ murniyanto@iaincurup.ac.id
}

\begin{abstract}
To create teachers with good social competence, the role of a school principal provides example. The success of the principal can be seen from his efforts to motivate the teacher's socil competence. Need to carry out several policies including planning, organizing, implementing, and monitoring. Of course many obstacles faced by a school principal. The next most basic obstacle is to unite differences of opinion between the teachers. In the efforts of the headmaster so that the relationship of social competence among teachers can run according to his expectations, the headmaster of the MIM 10 implements a reward and puinishment system for all teachers.
\end{abstract}

Keywords: Management, Principal, Social Competence

\begin{abstract}
Abstrak: Untuk menciptakan guru dengan kompetensi sosial yang baik, peran kepala sekolah memberikan contoh. Keberhasilan kepala sekolah dapat dilihat dari upayanya untuk memotivasi sosial guru. Perlu melakukan beberapa kebijakan termasuk perencanaan, pengorganisasian, implementasi dan pemantauan. Tentu saja banyak yang dihadapi oleh kepala sekolah, rintangan yang paling mendasar adalah menyatukan perbedaan pendapat antara guru. Dalam upaya kepala sekolah agar hubungan kompetensi sosial diantara para guru dapat berjalan sesuai dengan harapan, kepala sekolah MIM 10 menerapkan sistem penghargaan dan pemberian upah untuk semua guru.
\end{abstract}

Kata Kunci : Manajemen, Kepala Sekolah, Kompetensi Sosial

\section{PENDAHULUAN}

Dalam menghadapi kodisi sosial, kepala sekolah merupakan padanan dari school principal yang bertugas menjalankan principalship atau kepala sekolahan. Istilah kepala sekolah, artinya segala sesuatu yang berkaitan dengan tugas pokok dan fungsi sebagai kepala sekolah $^{1}$. Kepala sekolah tersusun dari dua kata, yaitu kepala dan sekolah. Kepala dapat diartikan sebagai ketua atau pemimpin dalam Setia),h.39

1 Hasan Basri,(2014),Kepemimpinan Kepala Sekolah,(Bandung:Pustaka

AR-RIAYAH : Jurnal Pendidikan Dasar vol. 4, no. 1, 2020

IAIN Curup - Bengkulu l p ISSN 2580-362X; e ISSN 2580-3611 http://journal.iaincurup.ac.id/index.php/JPD 
suatu organisasi atau lembaga ${ }^{2}$. Kepala sekolah orang yang terpilih secara selektif dari guru-guru yang ada disuatu sekolah ${ }^{3}$. Kepala sekolah sebagai pemimpin dilembaganya, maka dia harus mampu membawa lembaganya kearah tercapainya tujuan yang telah ditetapkan, dia harus mampu melihat adanya perubahan serta mampu melihat masa depan dalam kehidupan gelobalisasi yang lebih baik. Kepala sekolah harus bertanggung jawab atas kelancaran dan keberhasilan suatu urusan pengaturan dan pengelolahan secara formal kepada atasannya atau informal kepada masyarakat yang telah menitipkan anak didiknya.

Ada dua faktor, mengapa upaya perbaikan mutu belum tuntas. (1) belum menyediakan bahan ajar sepenuhnya, (2) penyedian sarana prasana belum cukup. Manajerial sangat menentukan bagaimana kualitas output dan tingkat kepuasan pelayanan lembaga pendidikan. Sebagai kepala sekolah dalam perannya memimpin suatu lembaga tentu memiliki beberapa strategi tersendiri dalam menjalankan tugasnya sebagai leader. Manajemen guru menentukan dalam menciptakan lingkungan kerja yang kondusif.

Manajer pendidikan, manusia dalam organisasi tidak terlepas dari sistem yang telah dibuat diorganisasi tersebut. Sistem itu dibuat berdasarkan kesepakatan anggotanya. Manajer pendidikan ialah yang paling berperan dalam pembentukan sistem tersebut, oleh karena itu seorang manajer diharapkan orang yang berwawasan luas dan mampu mengelola organisasi pendidikan ${ }^{4}$.

Manajemen adalah serangkaian kegiatan yang didesain untuk mencapai tujuan organisasi dengan menggunakan sumber daya secara efisien dan efektif dan dilakukan dalam lingkungan yang senantiasa berubah dari waktu ke waktu. Efektif berarti tercapai tujuan yang ditetapkan dan efisien berarti mencapai tujuan dengan menggunakan sedikit mungkin sumber daya yang tersedia.

2 Donni Juni Priansa,Rismi Somad,(2014),Manajemen Supervisi dan Kepemimpinan Kepala Sekolah, (Bandung: Alfabeta.),h.4

3 Amiruddin Siahaan,Dkk,(2012),Administrasi Satuan Pendidikan Pendekatan Sistemik Dalam Pengelolaan Pendidikan Untuk Meningkatkan Efektifitas Pencapaian Pada Satuan Pendidikan,(Medan:Pradana Publishing,),h.16

4 Yanto,m. (2020) Manajemen Sekolah Dalam Pengelolaan Kegiatan Guru

Bahasa Indonesia di Sekolah Dasar, Jurnal: Estetik,3 (1) 15-26 DOI:10.29240/estetik.V31i.1479

http://Journal.iaincurup.ac.id/index.php/estetik h.20 
Sebagaimana peran guru berdampak besar kepada peserta didik di lingkungan sekolah. Karena, jelaslah bahwa peserta didik menjadikan pengajar memberikan contoh suasana bergaul terhadap orang yang ada sekitarnya. Sehingga ini akan menambah kualitas autput yang akan diberikan dalam dunia pendidikan. Serta mampu berinteraksi dan berkomunikasi yang baik dengan masyarakat sekolah. Maka dari itu, peran dan fungsi dari seorang kepala sekolah perlu diterapkan sesuai pada porsinya dalam meningkatkan pembinaan terhadap pendidik yang ada dilingkungan sekolah dalam upayanya menuju kualitas sekolah yang baik dengan memiliki guru yang berkompeten.

Kompetensi guru ialah kumpulan ilmu, kekuatan dan kepercayaan yang ada pada guru serta ditunjukkan di dalam kelas. Kemampuan ini adalah sejumlah ilmu yang dimiliki guru dan kemampuan yang ada pada guru, sehingga dia memaknakan dan paham dalam menjalankan tugasnya sehari-hari. Kompetensi sosial guru adanya peran kepala sekolah sebagai penentu kebijakan yang digunakan oleh para pendidik yang ada disekolah dalam menciptakan hubungan yang efektif dan efisien serta masyarakat sekitarnya.

Berdasarkan observasi peneliti bahwa dilingkungan MIM 10 karang Anyar ini hubungan sosial yang terjalin harmonis dan sekilas terlihat baik. Pada jam istirahat beberapa guru bahkan hampir seluruh guru tidak beristirahat menggunakan waktu luangnya di ruang kantor guru masing-masing layaknya seperti yang dilakukan oleh guru-guru disekolah lainnya. Guru lebih menggunakan waktu istirahatnya untuk mengawas para murid kelasnya masing-masing.

\section{METODE PENELITIAN}

Penelitian kualitatif sebagai metode penelitian ilmu-ilmu sosial yang mengumpulkan dan menganalisis data berupa kata-kata (lisan maupun tulisan) dan perbuatan-perbuatan manusia serta peneliti tidak berusaha menghitung atau mengkuantifikasikan data kualitatif yang telah diperoleh dan dengan demikian tidak menganalisis angka-angka. Data yang dianalisis dalam penelitian kaulitatif adalah kata-kata dan perbuatan manusia ${ }^{5}$. Penelitian

5 Afrizal,(2015),Metode Penelitian Kualitatif Sebuah Upaya Mendukung Penggunaan Penelitian Kualitatif Dalam Berbagai Disiflin Ilmu,(Jakarta:Rajawali Pers.h.13 
merupakan hal dapat dilakukan dalam ilmu-ilmu sosial, dimana penelitian digunakan secara orisinil ${ }^{6}$.

\section{HASIL DAN PEMBAHASAN}

\section{Manajemen Kepala Sekolah}

Kepala sekolah sebagai pimpinan pendidikan harus memahami dan mengerti berbagai kedudukan, keinginan, keadaan dan apa yang diinginkan baik guru, pegawai yang ada lingkungan sekolah serta pembantu lainnya. Sehingga dengan adanya kerjasama yang baik dapat menghasilkan pikiran yang harmonis dalam usaha perbaikan sekolah. Kepala sekolah arah manajemen sekolah. Kepala sekolah motor penggerak penentu arah kebijakan sekolah, yang akan menentukan bagaimana tujuan sekolah dan pendidikan pada umumnya direalisasikan ${ }^{7}$. Ini berarti kepala sekolah dituntut untuk senantiasa untuk meningkatkan efektifitas kinerja sehingga dapat memberikan hasil yang memuaskan ${ }^{8}$. Dalam Undang-undang 1945 pasal 31 tertuang bahwa "setiap warga negara berhak mendapatkan pendidikan". Landasan konstitusional komitmen pendidikan inilah yang membuka peluang yang sebesar-besarnya bagi Bangsa Indonesia untuk berbuat baik bagi system pendidikan nasional melalui kebijakan bidang pemerintahan dan pembangunan, termasuk kebijakan otonomi daerah.

Kepala sekolah harus mampu melahirkan gagasan inovatif yang berguna untuk menghasilkan alternatif kebijakan dalam membangun". Sistem pendidikan yang efisien, bermutu dan sesuai dengan kebutuhan masyarakat dalam berbagai kehidupan ${ }^{10}$. Lembaga pendidikan merupakan sumber daya manusia yang menjadi subjek dan objek pembangunan yang perlu ditingkatkan mutunya melalui jalur pendidikan melalui fungsi, proses dan

6 Yanto, M., \& Fathurrochman, I. (2019).Manajemen Kebijakan Kepala Madrasah Dalam Meningkatkan Mutu Pendidikan.Jurnal Konseling Dan Pendidikan,7(3),123-130. http://doi.org/10.29210/138700.h.2

7 Beerkens,M.(2018).Evidence-based policy and higher eduction quality assurance: progress,pitfals and promise and promise. European journal of Higher Education,8(3),272-287. https://doi.org/10.1080/21568235.2018.1475248.h.1

8 Hidayat,A.,\& Machali,I (2018),The Handbook of education Management (2nd ed).Jakarta: Prenadamedia Group.h.1

9 Hidayat,A.,\& Machali,I (2018), The Handbook of education Management (2nd ed).Jakarta: Prenadamedia Group.h.1

10 Salto,D.J .(2018).quality Assurance through: accreditation:When resistance meets over -compliance. Higher-Education Quarterly, 72(2),7889,https://doi.org/10.1111/hequ.12151.h.1 
aktivitasnya bermuara pada pencapaian tujuan pendidikan nasional ${ }^{11}$. Jadi semua pimpinan, pendidik, dan tenaga kependidikan tugas dan wewenang yang jelas. Hal tersebut dapat dilihat dalam struktur organisasi sekolah yang di pasang pada papan ruang guru, diantara tanggung jawab kepala sekolah adalah sebagai educator, manajer, instruktur, supervisor dan leader ${ }^{12}$.

Dalam manajemen pendidikan, kepala sekolah harus berfungsi sebagai educator, manager, administrator, supervisor, leader, innovator dan motivator. Semua ini harus diketahui oleh pimpinan sekolah dan lebih penting lagi kepala sekolah harus mampu mengamalkan dan menjadikan tindakan nyata. Dengan demikian manajemen kepala sekolah sebagai manajerial adalah sebagai berikut:

1. Manajemen kurikulum, manajemen kurikulum sebagaimana agar proses pembelajaran dapat berjalan dengan baik.

2. Manajemen personalia, pada sekolah prinsipnya mengupayakan setiap warga sekolah dapat bekerja sama dan saling mendukung untuk mencapai tujuan.

3. Manajemen kesiswaan, pengelolaan peserta didik merupakan layanan yang sangat penting pada aturan, pengawasan dan layanan siswa di kelas.

4. Manajemen sarana dan prasarana pendidikan, sarana prasana pendidikan yang dilakukan secara periodik dan terencana.

5. Manajemen keuangan, disekolah terutama kegiatan sekolah dalam menggali dana, pengelolaan keuangan dikaitkan dengan program tahunan sekolah.

\section{Fungsi-fungsi manajemen}

Adapun fungsi manajemen adalah sebagai berikut:

1. Perencanaan, proses memikirkan dan menetapkan kegiatankegiatan atau program-program yang akan dilakukan pada masa yang akan dating untuk mencapai tujuan tertentu ${ }^{13}$.

2. Fungsi perencanaan antara lain menentukan tujuan atau kerangka tidakan yang diperlukan untuk mencapai tujuan

11 Davis,A.( 2017).Managerialism and the risky business of quality assurance in universities.Quality Assurance in Education.25(3),317328,https://doi.org/10.1108/QAE-06.2016-0027.h.2

12 Yanto, M. 2020, Manajemen Sekolah Dalam Pengelolaan Kegiatan Guru Babasa Indonesia di Sekolah Dasar , Jurnal Estetik, Vol. 1 hal. 15-26 DOI:10.29240/estetik.V31i.1479,http://Journal.iaincurup.ac.id/index.php/esteti k h.22 h.56

13 Sagala, Syaiful, 2011, Konsep dan Makna Pembelajaran, Bandung:Alfabeta, 
tertentu. Perencanaan dilakukan dengan mengkaji kekuatan dan kelemahan organisasi, menentukan kesempatan dan ancaman serta menentukan strategi, kebijakan dan program $^{14}$.

3. Organisasi, proses pembagian kerja kedalam tugas-tugas yang lebih kecil, membebankan tugas-tugas itu kepada orang yang lebih sesuai dengan kemampuannya, mengalokasikan sumberdaya dan mengkoordinasikannya dengan aktivitas pencapaian tujuan organisasi ${ }^{15}$.

4. Pengarahan, dorongan yang akan memberikan motivasi dalam suatu organisasi.

5. Pengawasan, erat kaitannya dengan perencanaan karena melalui pengawasan efektivitas manajemen dapat diukur.

Jadi merencanakan program kegiatan bersama warga sekolah berdasarkan panduan yang diberikan oleh dinas pendidikan yang terdiri dari kegiatan tahunan, semester, bulanan, mingguan harian dan kegiatan akhir tahun pelajaran. Fungsi dan peran kepala sekolah, ialah edukator, manajer, administrator, supervisor, leader, inovator, motivator. ${ }^{16}$

\section{Kompetensi Guru}

Kemampuan guru ialah keahlian pendidik dalam bergaul dan berkomunikasi dengan efektif dan efisien, sesama guru, peserta didik, dan lingkungan ${ }^{17}$. Kompetensi pendidik meliputi kompetensi: pedagogik, sosial, professional dan kepribadian. Tugas yang harus dimiliki sikap memberikan contoh, berkarya, memotivasi, memperhatikan serta melindungi.

\section{Karakteristik Guru}

Keberhasilan berhubungan dalam kompetensi sosial:

1. Target komunikasi, yaitu sasaran yang harus menyesuaikan irama dalam komunikasi sehingga mencapai sasaran yang diinginkan.

14 Rohiat,2010, Manajemen Sekolah: Teori dan Praktik, Bandung: Rafika Aditama,h.3

15 Ula,S.Shoimatul,(2013),Revolusi Belajar, Yogyakarta:Ar-Ruzz Media, h.18-19

16 Helmawati, 2014, Meningkatkan Kinerja Kepala Sekolah melahi Managerial Skills, Jakarta: Rineka Cipta.h.24-28

17 Ipon Dekawati, 2011, Manajemen Pengembangan Guru Profesional' Bandung: Resqi Pres.h.85 
2. Perilaku, yakni sasaran yang sedang terjadi dan sampai berakhir keadaan yang terjadi.

3. Kondisi, yakni dalam situasi hubungan yang sedang terjadi.

4. Tingkat,target yang harus di kuasai bahan komunikasi dalam dirinya.

5. Bagian-bagian Kompetensi Sosial

1. Kognitif,adalah keterampilan menjalin dan menjaga hubungan.

2. Adanya kesetaraan kebutuhan berhubungan dan penjagaan diri.

3. Kemampuan sosial dengan teman-teman,komunikasi personil dalam menjalin kompetensi sosial.

\section{PENUTUP.}

Kondisi Kompetensi Sosial madrasah ibtidaiyah Muhammadiyah 10 karang Anyar Rejang Lebong. Berdasarkan hasil penelitian bahwa kondisi kompetensi sosial pada saat ini sudah cukup memenuhi indikator-indikator karakeristik sebagai guru yang berkompetensi sosial. Contoh sebagaimana hubungan interaksi sosial guru terhadap sesama. Antara satu dengan yang lainnya punya ikatan yang kuat. Dalam melakukan beberapa kebijakan dalam manajemen kepala sekolah yaitu: Planing, dalam menerapkan prinsip kerjasama. Baik sesama guru, anak didik maupun wali dan masyarakat di sekitarnya. Organiæing, yaitu pembagian tugas mengajar, kelompok pengajian, rekreasi alam. Actuating, berupa sosialisasi dan mengemukakan pendapat dan bertukar informasi, sharring dan controling.

Adapun usaha menciptakan guru yang berkompeten dalam bidang sosial, tentu banyak kendala yang dihadapi oleh seorang kepala sekolah. Adapun kendala selanjutnya yang paling mendasar adalah menyatukan perbedaan pendapat antara para guru. Dalam usaha kepala sekolah agar hubungan kompetensi sosial sesama guru dapat berjalan sesuai dengan harapannya, kepala sekolah MIM 10 ini menerapkan system reward dan punishment bagi seluruh guru.

\section{DAFTAR PUSTAKA}

Abdul Wahab. (2011). Kepemimpinan Pendidikan dan Kecedasan Speritual, (Yogyakarta:Ar-Ruzz Media,)

Afrizal,(2015),Metode Penelitian Kualitatif Sebuah Upaya Mendukung Penggunaan Penelitian Kualitatif Dalam Berbagai Disiflin Ilmu,(Jakarta:Rajawali Pers. 
Amiruddin Siahaan,Dkk,(2012),Administrasi Satuan Pendidikan Pendekatan Sistemik Dalam Pengelolaan Pendidikan Untuk Meningkatkan Efektifitas Pencapaian Pada Satuan Pendidikan,(Medan:Pradana Publishing,)

Beerkens,M.(2018).Evidence-based policy and higher eduction quality assurance:progress,pitfals and promise and promise. European journal of Higher Education,8(3),272287. https://doi.org/10.1080/21568235.2018.1475248.

Donni Juni Priansa,Rismi Somad,(2014),Manajemen Supervisi dan Kepemimpinan Kepala Sekolah, (Bandung: Alfabeta.)

Davis,A.( 2017).Managerialism and the risky business of quality assurance in universities .Quality Assurance in Education.25(3),317-328,https://doi.org/10.1108/QAE06.2016-0027.

Fitri,E.,Erwinda,L.,\& Ifdil,I,(2018).Konsep Adiksi Game Online dan Dampaknya terhadap Masalah Mental Emosional Remaja serta Bimbingan dan Konseling.Jurnal Konseling dan Pendidikan, 6(2),211-219,https ://doi.org/1029210/127200

Hasan Basri,(2014),Kepemimpinan Kepala Sekolah,(Bandung:Pustaka Setia.

Helmawati, (2014)Meningkatkan Kinerja Kepala Sekolah melalui Managerial Skills, (Jakarta: Rineka Cipta.

Hidayat,A.,\& Machali,I (2018),The Handbook of education Management (2nd ed).Jakarta: Prenadamedia Group.

Ipon Dekawati, “(2011), Manajemen Pengembangan Guru Profesional” (Bandung: Resqi Pres.

Jurnal Pendidikan, 2013, https://lppmunigresblog.files.wordpress.com

Yanto, M., \& Fathurrochman, I. (2019).Manajemen Kebijakan Kepala Madrasah Dalam Meningkatkan Mutu Pendidikan.Jurnal Konseling Dan Pendidikan,7(3),123-130. http://doi.org/10.29210/138700.

Yanto,m.(2020) Manajemen Bahan Ajar Menulis Puisi Pada Tadris Bahasa Indonesia,Jurnal Tadbir,4(1),133150.https://scholar.geogle.co.id/cetb.

Yanto,m. (2020) Manajemen Sekolah Dalam Pengelolaan Kegiatan Guru Bahasa Indonesia di Sekolah Dasar, Jurnal : Estetik,3 (1) $15-26$

DOI:10.29240/estetik.V31i.1479http://Journal.iaincurup.ac.i d/index.php/estetik 
Yanto,m(2017)Manajemen dan Mutu Pembelajaran Bahasa

Indonesia di SMPN 4 Rejang Lebong,Jurnal Ar-riayah,1

(.2),192 DOI :http:/dx.doi.org/10.29240/jpd.v1i2-319

Rohiat,(2010),Manajemen Sekolah: Teori dan Praktik,(Bandung:

Rafika Aditama

Sagala,Syaiful,(2011)Konsep dan Makna

Pembelajaran,(Bandung:Alfabeta)

Salto,D.J .(2018).quality Assurance through: accreditation:When resistance meets over -compliance. Higher-Education Quarterly,72(2),78-

89,https://doi.org/10.1111/hequ.12151

Ula,S.Shoimatul,(2013),Revolusi Belajar,(Yogyakarta:Ar-Ruzz

Media) 